\title{
A COVID-19 E A EDUCAÇÃO PROFISSIONAL E TECNOLÓGICA: UM PANORAMA DAS AÇÕES DE ACOMPANHAMENTO E ENFRENTAMENTO DA PANDEMIA NOS INSTITUTOS FEDERAIS
}

\author{
Covid-19 and professional and technological \\ education: a panorama of following-up actions for \\ tackling pandemic in federal institutes
}

\author{
Mara Lúcia Castilho ${ }^{1}$ \\ Cláudio Nei Nascimento da Silva²
}

\begin{abstract}
Resumo. A pesquisa sobre a qual versa este trabalho objetivou apresentar um panorama das ações dos IF para mitigar os efeitos da pandemia nas atividades acadêmicas e fazer uma reflexão sobre a homogeneidade dessas ações no âmbito dos institutos quanto à igualdade de acesso à educação nesse contexto de excepcionalidade. Para tal, foram analisadas informações disponíveis nos sites dos 38 Institutos Federais de Educação (IF), a fim de se identificar: a existência de comitê/comissão para deliberação de ações no enfrentamento da Covid-19, seja institucional, nos campi ou em ambos; informações sobre a suspensão das atividades acadêmicas presenciais e a distância; informações sobre a suspensão do calendário acadêmico; e informações sobre a continuidade de atividades a distância e ou não-presenciais durante esse período dessa suspensão. Os resultados evidenciaram que essas instituições agiram rapidamente no âmbito interno, quer seja com a suspensão, parcial ou total, dos calendários acadêmicos, quer seja com a utilização de estratégias de ensino não-presencial. Percebeu-se que os IF responderam às demandas impostas e que, embora heterogêneas, as ações se voltaram, principalmente, para a preservação da saúde da comunidade acadêmica.

Palavras-chave: Covid-19. Institutos Federais (IF). Educação Profissional e Tecnológica
\end{abstract}

\begin{abstract}
The research on which this work deals with the objective of presenting an overview of the Federal Institutes actions to mitigate the effects of the pandemic in academic activities and to reflect on the homogeneity of these actions within the institutes regarding the equal access to education in this context of exceptionality. To this end, information available on the websites of the 38 Federal Institutes of Education was analyzed in order to identify: the existence of a committee / commission for deliberation of actions to face Covid-19, whether institutional, on campuses or both ; information on the suspension of on-site and distance academic activities; information on the suspension of the academic calendar; and information on the continuity of remote and in-person activities during this suspension period. The results showed that these institutions acted quickly internally, either with the partial or total suspension of academic calendars, or with the use of non-classroom teaching strategies. It was noticed that the FI responded to the demands imposed and that, although heterogeneous, the actions turned mainly to the preservation of the health of the academic community.

Key-words: Covid-19. Federal Institutes (IF). Professional and Technological Education
\end{abstract}

\footnotetext{
${ }^{1}$ Doutora em Linguística pela Universidade de Brasília (UnB), mestre em Educação pela Universidade Católica de Brasília (UCB), especialista em avaliação pela UnB e graduada em Letras português/inglês pelo Centro Universitário de Brasília (UniCEUB). Atualmente, é professora do Instituto Federal de Brasília (IFB). Orcid: http://orcid.org/0000-0002-8467-447X
}

2 Doutor em Ciência da Informação (UnB), Mestre em Educação (UCB), Pedagogo. Docente do Instituto Federal de Brasília (IFB). Orcid: http://orcid.org/0000-0003-3285-5268

Rev. Nova Paideia -Revista Interdisciplinar em Educação e Pesquisa Brasília/DF, v. 2, n. 3. Núm. Esp.. p. 18 - 34 - ANO 2020 ISSN 2674-5976

DOI: $10.36732 /$ riep.v2i3.60 


\section{Introdução}

A pandemia da Covid-19 foi declarada oficialmente em 11 de março de 2020, pelo diretor-geral da Organização Mundial da Saúde (OMS), Tedros Adhanom Ghebreyesus, em Genebra, na Suíça, e trouxe impactos significativos para todos os campos da sociedade, como indústria, comércio, turismo, setor de saúde e educação entre outros. No comunicado que fez à imprensa naquela data, o diretor-geral alertava: "Deixe-me resumir em quatro áreas principais: primeiro, preparem-se e estejam prontos. Segundo, detectem, protejam e tratem. Terceiro, reduzam a transmissão. Quarto, inovem e aprendam" (OMS, 2020).

Com a pandemia declarada, a maioria dos países optou por suspender as aulas e, em abril, 188 deles fecharam suas escolas, afetando, assim, pelo menos, 90\% dos estudantes em todo o mundo (WFP, 2020). Embora nem todos os países tenham realizado a suspensão total das atividades letivas, segundo a Unesco (2020), "esses fechamentos em todo o país estão provocando impacto".

Burgess e Sievertsen (2020, p. 1), ao refletirem sobre os impactos da Covid-19 na educação, chamaram a atenção para os dilemas enfrentados pelos formuladores de políticas educacionais a partir desta pandemia: "fechar escolas (reduzir o contato e salvar vidas) e mantê-las abertas (permitindo que os trabalhadores trabalhem e mantenham a economia)". Em outras palavras, essa reflexão pode ser realizada de maneira a se questionar o que é mais danoso ou arriscado: suspender as aulas e privar as crianças e jovens da aprendizagem de conteúdos escolares, da socialização com os demais, e de sua alimentação (no caso das crianças cuja principal alimentação é a fornecida pela escola), ou manter as aulas e converter a escola em um aglomerado humano propício à disseminação do coronavírus?

Se por um lado a pandemia da Covid-19 tem estimulado as instituições educacionais a se reinventarem, propondo tecnologias e métodos capazes de contornar as dificuldades próprias do novo contexto global, por outro, evidencia as desigualdades educacionais, quando, por exemplo, desconsidera as necessidades individuais dos estudantes, a dificuldade de acesso à tecnologia e à internet e o contexto familiar e doméstico, nem sempre favoráveis aos estudos. Por outro lado, quando essas crianças estão em casa, pode-se inferir que a mediação da aprendizagem é desigual, considerando-se cada família, pois conforme assinalam Burgess e Sievertsen (2020, p. 2), "provavelmente haverá disparidades substanciais entre as famílias na medida em que elas possam ajudar seus filhos a aprender". Além das disparidades que o contexto familiar reflete, não há nenhuma garantia de que o acesso à informação está

Rev. Nova Paideia -Revista Interdisciplinar em Educação e Pesquisa Brasília/DF, v. 2, n. 3. Núm. Esp.. p. 18 - 34 - ANO 2020 ISSN 2674-5976

DOI: $10.36732 /$ riep.v2i3.60 
democratizado entre os estudantes já que os obstáculos tecnológicos como acesso à internet depende das condições econômicas das famílias.

No caso específico do Brasil, em meados de maio de 2020, o Conselho Nacional de Educação (CNE) publicou uma nota de esclarecimento em que chama a atenção dos sistemas de ensino para os limites legais que as ações dos agentes públicos da área da educação devem observar quando tomarem medidas para enfrentamento da crise que a pandemia gerou no cenário educativo. Segundo essa nota, as instituições de educação básica e superior podem

propor formas de realização e reposição de dias e horas de efetivo trabalho escolar, em articulação com as normas e a legislação produzidas pelo correspondente órgão de supervisão permanente do seu sistema de ensino e de dirigentes municipais, estaduais e do Distrito Federal (BRASIL, 2020a, p. 1.)

A referida nota também faz menção à utilização da modalidade de educação a distância (EaD) em instituições de educação superior "como alternativa à organização pedagógica e curricular de seus cursos de graduação presenciais” (BRASIL, 2020a, p. 1). Além disso, essa nota do CNE esclarece que a competência para autorizar a utilização da educação a distância no ensino fundamental e médio é das autoridades municipais e estaduais, responsáveis, nos termos da Lei de Diretrizes e Bases da Educação Nacional de 1996 (LDB), pela oferta desses níveis de ensino, desde que observadas os limites legais pertinentes.

Posteriormente a essa nota, em primeiro de junho de 2020, foi homologado Parecer 5/2020 do Conselho Pleno (BRASIL, 2020b) por esse mesmo Conselho sobre a reorganização de calendário escolar e sobre a possibilidade de cômputo de atividades não presenciais para o cumprimento da carga horária mínima anual, em razão da Pandemia da Covid-19.

De acordo com as normativas do Ministério da Educação (MEC), de dezembro de 2019, os cursos de graduação podem ofertar até 40\% da carga horária total dos cursos presenciais a distância. No caso do ensino fundamental, o parágrafo $4^{\circ}$ do artigo 32 da LDB esclarece que o ensino fundamental deve ser ofertado de modo presencial, mas admite que o ensino a distância pode vir a ser utilizado "como complementação da aprendizagem ou em situações emergenciais" (BRASIL, 1996a). Para o ensino médio, a LDB assegura no parágrafo 11 do artigo 36 que os sistemas de ensino poderão firmar convênios com instituições de educação a distância para que estas possam oferecer serviços que vão desde atividades de demonstração prática, cursos, trabalhos supervisionados e cursos a distância ou presenciais mediados por tecnologias.

Diante desse contexto de dificuldades e desafios, de exclusões e oportunidades, de passividade e enfrentamento, realizou-se um estudo acerca das ações da rede

Rev. Nova Paideia -Revista Interdisciplinar em Educação e Pesquisa Brasília/DF, v. 2, n. 3. Núm. Esp.. p. 18 - 34 - ANO 2020 ISSN 2674-5976

DOI: $10.36732 /$ riep.v2i3.60 
federal de educação científica e tecnológica para identificar as ações realizadas pelos institutos federais (IF) relacionadas a três aspectos: a criação de comitês de prevenção e acompanhamento; a suspensão de atividades acadêmicas e do calendário letivo; e eventuais estratégias para continuidade das atividades educacionais.

Nesse sentido, este trabalho tem como objetivos apresentar o panorama das ações para mitigar os efeitos da pandemia referentes às atividades acadêmicas dos IFs e fazer uma reflexão sobre a homogeneidade dessas ações no âmbito dos institutos quanto à igualdade de acesso à educação nesse contexto de excepcionalidade.

\section{0 acesso remoto das famílias e das escolas brasileiras}

O artigo 206 da Constituição Federal discorre sobre a igualdade de condições de acesso e permanência na escola, sem a qual, o processo de ensino pode ser prejudicado. Nesse tempo de pandemia, as decisões acerca dessa igualdade têm desafiado ainda mais os gestores e educadores, pois o acesso dos estudantes aos recursos virtuais, principalmente das redes públicas de ensino e aqueles com maior índice de vulnerabilidade, parece ser um dos grandes empecilhos da oferta das atividades remotas. Um destes desafios é não deixar os estudantes serem marginalizados em razão da falta de acesso à internet e a dispositivos eletrônicos, isto é, sem condições de realização dessas atividades. A permanência na escola depende, também, das condições para realização de tarefas, caso contrário, isso pode até ser um elemento para ampliar os percentuais de evasão.

Outra questão a ser ponderada é o letramento dos estudantes para fazer uso desses ambientes virtuais de aprendizagem, pois muitos podem nunca ter tido contato com esse tipo de programa ou aplicativo. Há que se considerar, inclusive, a possibilidade de os estudantes acessarem a internet apenas por meio de pacote de dados das operadoras de celulares e isso também pode ser um entrave, uma vez que o download das atividades pode ser limitado em razão da baixa qualidade do sinal disponível e do tipo de pacote de dados contratado por ele ou por sua família, que pode não ser suficiente para essa demanda.

Na literatura científica, esse tema é recorrente em estudos que relacionam a desigualdade social com a desigualdade de condições de acesso à tecnologia. Ao buscar traçar um retrato da exclusão digital na sociedade brasileira, Almeida e outros (2005, p. 56) afirmaram que essa situação pode ser vista por diferentes perspectivas, "tanto pelo fato de não ter um computador, ou por não saber utilizá-lo (saber ler) ou ainda por falta de um conhecimento mínimo para manipular a tecnologia com a qual convivese no dia-a-dia", indicando, já no início da década, que o problema não pode ser visto apenas sob o ponto de vista tecnológico.

Rev. Nova Paideia -Revista Interdisciplinar em Educação e Pesquisa Brasília/DF, v. 2, n. 3. Núm. Esp.. p. 18 - 34 - ANO 2020 ISSN 2674-5976

DOI: $10.36732 /$ riep.v2i3.60 
Em 2019, de acordo com a pesquisa realizada pelo Núcleo de Informação e Coordenação do Ponto BR - NIC.br, 71\% dos domicílios no Brasil possuíam acesso a internet. Na área urbana, 75\% dos domicílios possuíam acesso remoto e, na rural, 51\%. Esses dados variam de acordo com cada região brasileira, sendo o menor acesso registrado, nessa pesquisa, o da região Nordeste, cujo percentual total de acesso à internet era de $65 \%$. Se considerarmos a classe social DE, esse percentual cai ainda mais (50\%). Esses dados revelam que a decisão pela continuidade dos estudos na modalidade a distância, neste período de pandemia, levaria, pelo menos, a quinta parte dos estudantes a serem excluídos do processo educacional, seja pela falta de internet, pela falta de letramento ou até por outras demandas familiares, como, auxiliar na produção de recursos para se sustentarem, isto é, ir em busca de trabalho para suprir as necessidades básicas de seus familiares.

Além do acesso aos recursos remotos nas residências dos brasileiros, quando analisados os dados da infraestrutura das escolas no Brasil, a disponibilização desse recurso nas instituições de ensino também deve ser levada em consideração, pois o ensino por meio de ambientes virtuais depende desse acesso enquanto os estudantes estão nas escolas. De acordo com os dados do Censo da Educação realizado pelo Instituto Nacional de Pesquisas Educacionais Anísio Teixeira (INEP), sobre a infraestrutura dessas instituições brasileiras, os recursos tecnológicos disponíveis para uso da comunidade acadêmica, professores e estudantes, em 2018, nas escolas municipais era de 21,1\% (BRASIL, 2019, p. 14); apenas 59,2\% das escolas estaduais disponibilizavam acesso à internet a seus estudantes, sendo que, para o ensino e aprendizagem, esse percentual era $64 \%$ para as escolas estaduais e de $29,6 \%$ para as escolas municipais. Na rede federal de educação básica, por sua vez, de acordo com os dados do INEP, em 2018, 83\% dos estabelecimentos de ensino disponibilizavam acesso à internet aos estudantes e, para o ensino e aprendizagem, esse percentual era de $80,9 \%$. A partir desses dados, infere-seque a inclusão dos estudantes e a igualdade de condições para o ensino, referenciado no texto constitucional de 1988, ainda é um problema a ser resolvido, mesmo após 22 anos de sua promulgação. A partir dos dados referenciados, entende-se, também, que o desenvolvimento de habilidades em ambientes remotos pode estar comprometido, podendo interferir no rendimento das atividades atribuídas aos estudantes por meio desses ambientes.

Nesse sentido, considera-se, conforme apontado por Assman (2000), que a mera disponibilização de informação na rede não é suficiente para a construção de conhecimentos. O desenvolvimento intelectual (como também o moral, afetivo, cultural) dos estudantes não depende, exclusivamente, de boa internet ou de acesso à informação. É necessário um saber fazer, isto é, o desenvolvimento de competências e habilidades que promovam a capacidade de discernimento, de crítica e de construção de saberes necessários à vida em uma sociedade altamente mediada por tecnologias.

Rev. Nova Paideia -Revista Interdisciplinar em Educação e Pesquisa Brasília/DF, v. 2, n. 3. Núm. Esp.. p. 18 - 34 - ANO 2020 ISSN 2674-5976

DOI: $10.36732 /$ riep.v2i3.60 
Além disso, os problemas relacionados à superabundância de informação pela internet não são novos. Moran (1997), há mais de duas décadas, já chamava a atenção para os dilemas que um entusiasmo ingênuo pode trazer:

Criam-se todos os dias mais de 140 mil novas páginas de informações e serviços na rede. Há informações demais e conhecimento de menos no uso da internet na educação. E há certa confusão entre informação e conhecimento. Temos muitos dados, muitas informações disponíveis. Na informação, organizamos os dados dentro de uma lógica, de um código, de uma estrutura determinada. Conhecer é integrar a informação no nosso referencial, no nosso paradigma, apropriando-a, tornando-a significativa para nós. 0 conhecimento não se passa, o conhecimento se cria, constrói-se (MORAN, 1997, p. 7).

Além da dificuldade de acesso dos estudantes a ambientes virtuais e à internet, há outro entrave a ser considerado, os docentes. Os próprios docentes parecem não ter conhecimentos e habilidades para trabalhar com ambientes virtuais de aprendizagem, haja vista a quantidade de cursos ofertados pelas escolas de formação docente para o ensino a distância.

Esses problemas de acesso remoto, de familiaridade com ambientes virtuais de ensino e de capacitação docente foram levados em consideração pelo CNE. Fundamentado, entre outros, no parecer CNE/CEB no 5, de maio de 1997, esse Conselho ratifica o entendimento anterior, de que a sala de aula pode extrapolar os limites das quatro paredes físicas, desde que haja orientação por professores habilitados. Assim, no Parecer CNE/CP no 5/2020, de 28 de abril de 2020, homologado em 1ำ de junho do corrente ano, traz outro entendimento sobre a utilização da modalidade de educação a distância (EaD), utilizado na Nota de Esclarecimento publicada em março deste ano, e passa a intitular essas atividades como 'não presenciais', e salienta:

que a realização das atividades pedagógicas não presenciais não se caracteriza pela mera substituição das aulas presenciais e sim pelo uso de práticas pedagógicas mediadas ou não por tecnologias digitais de informação e comunicação que possibilitem o desenvolvimento de objetivos de aprendizagem e habilidades previstas na BNCC, currículos e propostas pedagógicas passíveis de serem alcançadas através dessas práticas (BRASIL, 2019, p. 8).

Dessa maneira, esse Conselho permitiu a flexibilização para a realização de atividades pedagógicas não presenciais, possibilitando que estas sejam realizadas por meio digitais, por meio de programas de TV e rádio; pela utilização de material impresso a ser distribuído, ou pela orientação de leituras, projetos, pesquisas, atividades e exercícios indicados em materiais didáticos.

Rev. Nova Paideia -Revista Interdisciplinar em Educação e Pesquisa Brasília/DF, v. 2, n. 3. Núm. Esp.. p. 18 - 34 - ANO 2020 ISSN 2674-5976

DOI: $10.36732 /$ riep.v2i3.60 
As escolas, quando da reorganização dos calendários acadêmicos suspensos neste período de pandemia declarada, poderão considerar essas orientações no cumprimento da carga horária mínima estabelecida em lei. Essa mudança conceitual, com certeza, facilitará não só planejamento das instituições de ensino como também a inclusão de estudantes sem acesso tecnológico para a realização das atividades educacionais.

\section{Percurso metodológico}

Para atingir os objetivos propostos, realizou-se pesquisa qualitativa, de caráter exploratório, em 2020, no período de 27-05 a 13-06, a partir da análise das informações disponíveis nos sites dos 38 IFs, a fim de se identificar a existência de comitê/comissão para deliberação de ações no enfrentamento da Covid-19, seja institucional ou em cada campus ou em ambos, além de obter informações sobre a suspensão das atividades acadêmicas presenciais e a distância,o calendário, a continuidade de atividades a distância, virtuais ou não presenciais, durante o período da suspensão. Cabe esclarecer que as informações garimpadas em alguns sites desses IFs foram de difícil acesso e, muitas das vezes, foram encontradas no ambiente intitulado notícias. Por esse motivo, é possível que algumas datas encontradas no ambiente virtual de cada um desses IFs podem estar registradas com atraso de um ou dois dias. Todavia, foi possível sistematizar os dados previstos no início da pesquisa, conforme citado acima. Como a suspensão das atividades acadêmicas presenciais foi sendo monitorada, foram encontrados diversos documentos prorrogando a data inicial de suspensão das atividades presenciais e ou não presenciais. Nesse sentido, os pesquisadores decidiram registrar as informações referentes aos períodos de forma sintetizada, isto é, seu início e, quando havia, a data de término do respectivo período. Ratifica-se, ainda, que, como as decisões estão sendo tomadas de maneira muito dinâmica, a partir do acompanhamento e realidade de cada IF, que as informações foram obtidas até o dia 13 de junho.

Os dados encontrados foram sistematizados e organizados em tabelas e quadros, conforme serão descritos na seção seguinte.

\section{Resultados e discussão}

Uma das primeiras ações dos institutos federais para enfrentamento da pandemia de Covid-19 foi a criação de comitês institucionais formados por seus servidores. Esses comitês, em geral, tiveram o objetivo de monitorar o impacto da doença na instituição e, ao mesmo tempo, propor ações que pudessem proteger a comunidade acadêmica das consequências da pandemia. A instauração desses colegiados seguiu a declaração de pandemia dada pela OMS e as orientações do

Rev. Nova Paideia -Revista Interdisciplinar em Educação e Pesquisa Brasília/DF, v. 2, n. 3. Núm. Esp.. p. 18 - 34 - ANO 2020 ISSN 2674-5976

DOI: $10.36732 /$ riep.v2i3.60 
Ministério da Educação (MEC), que, em 11 de março de 2020, publicou a Portaria no 329, instituindo o Comitê Operativo de emergência - COE/MEC, com o objetivo de "gerenciar questões inerentes a assuntos sensíveis, de repercussão nacional" (BRASIL, 2020b, artigo $1^{\mathfrak{9}}$ ), tendo se reunido pela primeira vez em 16 de março. De acordo com essa portaria, esse comitê é composto, entre outros, por dois representantes do Conselho Nacional das Instituições da Rede Federal de Educação Profissional e Tecnológica - CONIF. A Tabela 1 apresenta as datas de criação desses comitês nos IFs.

Tabela 1 - Comitês institucionais para ações de enfrentamento da Covid-19, por data de criação nos IFs.

\begin{tabular}{lll}
\hline Data & IFs & Quantidade \\
\hline $12 / 03 / 2020$ & IFMT, IFPR, IFRJ, IFSul-rio-grandense, IFRO, & 6 \\
& IFC & \\
$13 / 03 / 2020$ & IFBA, IFBaiano, IFB, IFMS, IFPB, IFPI, IFSP, & 9 \\
& IFSE, IFTO & \\
$16 / 03 / 2020$ & IFAC, IFAM, IFMA, IFNMG, IFTM, IFFAR, IFRO, & 8 \\
$17 / 03 / 2020$ & IFGO & 1 \\
$18 / 03 / 2020$ & IFMG, IFRN, IFCE* & 3 \\
$19 / 03 / 2020$ & IFPA & 1 \\
$21 / 03 / 2020$ & IFRS & 1 \\
$23 / 03 / 2020$ & IFG, IFPE & 2 \\
$06 / 06 / 2020$ & IFSC & 1 \\
2016 & IFES** & 1 \\
$* * *$ & IFAL, IFAP, IFSuldeminas, IFSudesteMG & 4 \\
$* * * *$ & IFGoiano & 1 \\
Total & & 38 \\
\hline
\end{tabular}

Fonte: Dados da pesquisa, 2020.

*Não foi localiza portaria instituindo comitê. Data definida pela Ata da segunda reunião, disponibilizada no site.

** Comitê de crise foi instituído em 2016, sendo atualizado para atuação na pandemia.

*** Não foram encontradas informações referentes à criação de comitê para ações de enfrentamento da pandemia de Covid-19.

**** Encontrada informações sobre ações do comitê, entretanto, não foi encontrado documento formalizando sua criação.

Conforme demonstra a Tabela 1, no primeiro dia depois de decretada pandemia e instituído o COE/MEC, seis institutos federais já os instituíram para enfrentamento da doença, sendo eles IFMT, IFPR, IFRJ, IFSul-rio-grandense, IFRO, IFC. No dia seguinte,

Rev. Nova Paideia -Revista Interdisciplinar em Educação e Pesquisa Brasília/DF, v. 2, n. 3. Núm. Esp.. p. 18 - 34 - ANO 2020 ISSN 2674-5976

DOI: $10.36732 /$ riep.v2i3.60 
mais nove institutos (IFBA, IFBaiano, IFB, IFMS, IFPB, IFPI, IFSP, IFSE, IFTO) o haviam instituído e, no dia útil seguinte, em 16 de março, segunda-feira, oito institutos o fizeram (IFAC, IFAM, IFMA, IFNMG, IFTM, IFGO, IFFAR, IFRO), totalizando, assim, 23 institutos. Dez IFs organizaram seus comitês entre 17 de março até o início de junho. Não foram encontradas informações a respeito dos comitês e ou comissões em pelo menos cinco sites, conforme Tabela 1. Essas informações revelam que os IF atenderam às orientações do MEC e do CONIF, instituindo grupos colegiados para pensar ações de mitigação dos impactos da pandemia em suas comunidades para, entre outras coisas, sistematizar as ações realizadas por cada um deles.

Com a pandemia, conforme já relatado anteriormente e de acordo com o World Food Programme (WFP), as aulas presenciais em pelo menos 188 países, até abril, foram suspensas. No Brasil, os estados também decidiram pela interrupção das aulas nas instituições de ensino de todos os níveis, como medida preventiva, e, nos IFs, elas começaram a ser suspensas em meados de março. A Tabela 2 demonstra o período de suspensão das atividades presenciais nos 38 IFs.

Tabela 2 - Levantamento da data de suspensão das atividades acadêmicas presenciais

\begin{tabular}{|c|c|c|c|c|}
\hline & 13 a $16 / 03$ & 17 a $19 / 03$ & 20 a $23 / 03$ & 24 a $28 / 03$ \\
\hline IF & $\begin{array}{l}\text { IFG, IFRS, IFF, } \\
\text { IFRJ,IFSC, IFAP, } \\
\text { IFPR, IFSP, IFPE }\end{array}$ & $\begin{array}{l}\text { IF Catarinense, IFPI, } \\
\text { IFES, IFFar, IFTO, } \\
\text { IFTM, IFSul de Minas, } \\
\text { IFAM, IFMG, IFSul-rio- } \\
\text { grandense, IFAL, IFRR, } \\
\text { IFAC, IFBA, IFBaiano, } \\
\text { IFB, IFMA, IF Norte de } \\
\text { Minas, IF Sudeste de } \\
\text { Minas, IFPB, IF Sertão } \\
\text { Pernambucano, IFSE }\end{array}$ & $\begin{array}{l}\text { IFMS,IFCE, IFRO, } \\
\text { IFRN }\end{array}$ & IFGoiano, IFPA \\
\hline Total & 9 & 23 & 4 & 2 \\
\hline
\end{tabular}

Fonte: Dados da pesquisa, 2020

Conforme demonstrado na Tabela 2, pelo menos 9 IF (IFG, IFRS, IFF, IFRJ, IFSC, IFAP, IFPR, IFSP, IFPE) suspenderem suas atividades acadêmicas presenciais entre 13 e 16 de março. Na semana seguinte, 23 IFs suspenderam suas atividades presenciais e os demais IFs suspenderam-nas até 28 de março. Conforme esclarecido anteriormente, os atos normativos referentes à suspensão das atividades dos IFs foram sendo

Rev. Nova Paideia -Revista Interdisciplinar em Educação e Pesquisa Brasília/DF, v. 2, n. 3. Núm. Esp.. p. 18 - 34 - ANO 2020 ISSN 2674-5976

DOI: $10.36732 /$ riep.v2i3.60 
monitorados e esses atos vêm sendo constantemente renovados até hoje. Esses dados revelam que a interrupção nas atividades acadêmicas presenciais seguiu o movimento mundial de ações governamentais de distanciamento social de maneira a diminuir a transmissão do coronavírus e, assim, tentar mitigar os efeitos sobre a saúde da população. Essas ações dos IFs também foram tomadas a fim de prevenir a proliferação da doença e proteger as vidas da comunidade interna. Foram medidas muito importantes que seguiram as recomendações dos governos locais, do MEC e do Ministério da Saúde.

Com a suspensão das atividades presenciais nessas instituições federais, como consequência, houve debates sobre a suspensão dos calendários acadêmicos e sobre a utilização de ambientes virtuais ou outros recursos para suprir a carga horária a ser cumprida durante o ano letivo vigente. Enquanto instituições públicas e levando-se em consideração possíveis dificuldades administrativas, a maioria dos IFs decidiu suspender seus calendários acadêmicos. A Tabela 3 demonstra a realidade sobre essa ação em todos os IF durante esse período de pandemia declarada.

Tabela 3 - Levantamento sobre a suspensão do calendário acadêmico dos IFs

\begin{tabular}{|c|c|c|c|c|}
\hline & $\begin{array}{l}\text { Por tempo } \\
\text { indeterminado }\end{array}$ & $\begin{array}{l}\text { Por um período } \\
\text { determinado }\end{array}$ & $\begin{array}{l}\text { Mantido o } \\
\text { calendário }\end{array}$ & $\begin{array}{l}\text { Tentativa de } \\
\text { manutenção ou } \\
\text { retomada das } \\
\text { atividades }\end{array}$ \\
\hline IF & $\begin{array}{l}\text { IFAC, IFBA, } \\
\text { IFBaiano, IFB, IFG, } \\
\text { IFMA, IFMG } 1 \text {, IF } \\
\text { Norte de Minas, IF } \\
\text { Sudeste de Minas, } \\
\text { IFPA }^{2} \text {, IFPB, IFRN, } \\
\text { IFSE, IFSP, IFPE, } \\
\text { IFPI, IF Sertão } \\
\text { Pernambucano }\end{array}$ & $\begin{array}{l}\text { IFSul-rio- } \\
\text { grandense, IFES }{ }^{3} \text {, } \\
\text { IFRS, IFAL, IFCE, } \\
\text { IFGoiano }^{4} \text { IFMT, } \\
\text { IFPR, IFRJ, IFF, } \\
\text { IFRO, IFRR }\end{array}$ & $\begin{array}{l}\text { IFAM, IFSC, } \\
\text { IFMS, IFSul de } \\
\text { Minas, } \text { IFTM }^{5}\end{array}$ & $\begin{array}{l}\text { IFAP, IFFar6, IFTO7, } \\
\text { IF Catarinense }^{8}\end{array}$ \\
\hline Total & 17 & 12 & 5 & 4 \\
\hline
\end{tabular}

Fonte: Dados da pesquisa, 2020

116 campi suspenderam por tempo indeterminado. Apenas dois campi não suspenderam o calendário. 2Suspenso a partir de 28/03, mas as atividades não presenciais da graduação foram mantidas até integralizar $40 \%$ da carga horária.

${ }^{3}$ Suspenso até 17/4, quando o calendário foi retomado com atividades a distância/ não presencial. ${ }^{4}$ Suspenso até 19/04, sendo retomado, a partir de 20/04/20, a critério de cada campus, de forma não presencial, com a utilização de meios e ferramentas de tecnologias de informação e comunicação por meio da Educação a Distância (EaD), centralizando no AVA Institucional (Moodle).

${ }^{5}$ Alterado apenas o término do primeiro semestre em 14/08. A princípio, o calendário do segundo semestre está mantido. 
${ }^{6}$ Suspenso a partir de 15/05 por tempo indeterminado.

${ }^{7}$ Suspenso a partir de $1 / 06$.

8Suspenso no período de 16/04 a 15/05.

A manutenção do calendário por parte de alguns IFs (IFAM, IFSC, IFMS, IFSul de Minas, IFTM) não significou, contudo, a manutenção das atividades presenciais. Em nota publicada em 10 de junho, o IFSC, por exemplo, reforçou que as "atividades pedagógicas e administrativas presenciais seguem suspensas até 31 de julho" (BRASIL, 2020d). Situação semelhante ocorreu no IFMS. Nesta última instituição, decidiu-se que "a suspensão das atividades presenciais será prorrogada até 30 de junho. Assim, os estudantes da instituição continuam tendo aulas em ambientes virtuais de ensino e servidores permanecem em home office até a próxima deliberação" (BRASIL, 2020e). No IFAM, as atividades acadêmicas presenciais foram substituídas por atividades remotas, garantindo-se suporte tecnológico, digital ou não, e pedagógico apropriado (BRASIL, 2020f). Para este instituto, àqueles com dificuldade de acesso remoto foram permitidos estudos dirigidos. A responsabilidade pelo monitoramento dessas atividades ficou a cargo de cada campus. Já o Instituto Federal do Triângulo Mineiro, alterou apenas a data de término do primeiro semestre de 2020, mantendo-se, até a data do fim desta pesquisa, o calendário previsto para o segundo semestre letivo do ano em curso.

Outros IF, como IFAP, IFFar, IFTO, IF Catarinense, conforme demonstra a Tabela 3, parecem ter tentado evitar a suspensão dos calendários, mas, se observarmos os dados desta tabela e os dados do Quadro 1, infere-se que o monitoramento da continuidade das atividades remotas deve ter contribuído para a decisão da suspensão de seus calendários. Conforme podemos observar no Quadro 1, esses quatro IFs mantiveram as atividades em ambientes virtuais até maio, momento em que estas foram suspensas, coincidindo com a data de suspensão de seus calendários.

Pelo menos 17 IFs suspenderam seus calendários, a partir do mês de março, por tempo indeterminado. Os demais 12 IFs suspenderam seus calendários por tempo determinado, sendo a data limite dessa suspensão coincidente com o final do calendário previsto para o primeiro semestre.

Como a situação da pandemia foi heterogênea e cada estado brasileiro adotou medidas distintas para mitigação da doença, é possível que cada IF tenha seguido as orientações dos governos locais e isso, com certeza, também deve ter interferido nessas realidades, uma vez que elas interferem, inclusive no acesso dos estudantes ao campus, pois dependem do transporte público e da liberação, pelo estado, de vale transporte para tal fim.

Quanto às atividades remotas e ou não presenciais, o Quadro 1 traz a decisão de cada IF, sendo possível perceber não haver unicidade dessas medidas na rede federal

Rev. Nova Paideia -Revista Interdisciplinar em Educação e Pesquisa Brasília/DF, v. 2, n. 3. Núm. Esp.. p. 18 - 34 - ANO 2020 ISSN 2674-5976

DOI: $10.36732 /$ riep.v2i3.60 
como um todo, da mesma maneira que houve unicidade na decisão referente à suspensão dos calendários acadêmicos dessas instituições federais.

Quadro 1 - Levantamento sobre a continuidade de atividades EaD ou não presencial

\begin{tabular}{|c|c|c|}
\hline Instituto & $\begin{array}{l}\text { Atividades EaD/não presencial para } \\
\text { graduação }\end{array}$ & $\begin{array}{l}\text { Atividades EaD/não presencial para } \\
\text { cursos técnicos (EMI e demais cursos) }\end{array}$ \\
\hline IFAC & Suspensas & Suspensas \\
\hline IFAL & Suspensas & Suspensas \\
\hline IFAM & Mantidas & Mantidas \\
\hline IFAP & $\begin{array}{l}\text { Mantidas até atingir } 40 \% \text { (conforme } \\
\text { portaria MEC } 2117 / 2019 \text { (até o limite de } \\
40 \% \text { da carga horária total do curso) e } \\
\text { Portaria MEC } 245 / 2020 \text { ) }\end{array}$ & Suspensas \\
\hline IFB & Suspensas & Suspensas \\
\hline IFBA & Suspensas & Suspensas \\
\hline IFBaiano & Suspensas & Suspensas \\
\hline $\begin{array}{l}\text { IFCatarine } \\
\text { nse }\end{array}$ & Retomadas a partir de 18/05 & Retomadas a partir de $1 / 6$ \\
\hline IFCE & Retomada gradativa a partir de $28 / 05$ & Retomadas gradativa a partir de $28 / 05$ \\
\hline IFES & Retomadas a partir de $17 / 4$ & Suspensas \\
\hline IFF & Suspensas & Suspensas \\
\hline IFFarr & Mantidas até $15 / 05$ & Mantido até 15/05 \\
\hline IFG & Suspensas & Suspensas \\
\hline IFGoiano & Retomadas a partir de 20 de abril & $\begin{array}{l}\text { Retomadas a partir de } 20 \text { de abril, limitada } \\
\text { a } 60 \% \text { da carga horária total da disciplina } \\
\text { para os cursos de educação profissional } \\
\text { técnica de nível médio. }\end{array}$ \\
\hline IFMA & Suspensas & Suspensas \\
\hline IFMG & $\begin{array}{l}\text { Mantidas em } 2 \text { campi, Suspensas nos } \\
\text { demais }\end{array}$ & $\begin{array}{l}\text { Mantidas em } 2 \text { campi, Suspensas nos } \\
\text { demais }\end{array}$ \\
\hline IFMS & Mantidas & Mantidas \\
\hline IFMT & Suspensas & Suspensas \\
\hline $\begin{array}{l}\text { IFNorte de } \\
\text { Minas }\end{array}$ & Suspensas & Suspensas \\
\hline IFPA & Mantidas até completar $40 \%$ da carga & Suspensas a partir $28 / 03$ \\
\hline
\end{tabular}




\begin{tabular}{|c|c|c|}
\hline & $\begin{array}{l}\text { horária não presencial, conforme } \\
\text { legislação. }\end{array}$ & \\
\hline IFPB & Suspensas & Suspensas \\
\hline IFPE & Suspensas a partir de 18/05 & Suspensas a partir de $18 / 05$ \\
\hline IFPI & $\begin{array}{l}\text { Iniciadas em } 11 / 05 \text { até o limite de } 40 \% \\
\text { da carga horária. }\end{array}$ & $\begin{array}{l}\text { Iniciada em } 11 / 05 \text { até o limite } 20 \% \text { carga } \\
\text { horária para cursos técnicos. }\end{array}$ \\
\hline IFPR & Mantidas no limite da legislação & Mantidas no limite da legislação \\
\hline IFRJ & Mantidas até 30/06 & Mantidas até 30/06 \\
\hline IFRN & Suspensas & Suspensas \\
\hline IFRO & Suspensas a partir de 16/04 & Suspensas partir de $16 / 04$ \\
\hline IFRR & Retomadas em 1/06 em alguns campi. & Retomadas em 1/06 em alguns campi. \\
\hline IFRS & Suspensas & Suspensas \\
\hline IFSC & Mantidas & Mantida \\
\hline IFSE & Suspensas & Suspensas \\
\hline $\begin{array}{l}\text { IFSertão } \\
\text { Pernambu } \\
\text { cano }\end{array}$ & Suspensas & Suspensas \\
\hline IFSP & $\begin{array}{l}\text { Retomadas em } 29 / 05 / 2020 \text { para os } \\
\text { cursos que tenham EaD previstas no PPC. }\end{array}$ & $\begin{array}{l}\text { Retomadas em } 29 / 05 / 2020 \text { para os cursos } \\
\text { que tenham EaD previstas no PPC. }\end{array}$ \\
\hline $\begin{array}{l}\text { IFSudeste } \\
\text { de Minas }\end{array}$ & Suspensas & Suspensas \\
\hline $\begin{array}{l}\text { IFSul de } \\
\text { Minas }\end{array}$ & Mantidas & Mantidas \\
\hline $\begin{array}{l}\text { IFSul-Rio- } \\
\text { Grandens } \\
\text { e }\end{array}$ & Retomadas em 18/05. & Retomadas em 18/05. \\
\hline IFTM & $\begin{array}{l}\text { Mantidas até } 1^{\text {o }} \text { de junho (Suspensas } \\
\text { temporariamente de } 1^{\circ} \text { a } 19 / 06 \text { ) }\end{array}$ & $\begin{array}{l}\text { Mantidas até } 1^{\text {o }} \text { de junho (Suspensas } \\
\text { temporariamente de } 1^{\circ} \text { a } 19 / 06 \text { ) }\end{array}$ \\
\hline IFTO & Mantidas até 29/05 & Mantidas até 29/05 \\
\hline
\end{tabular}

Fonte: Dados da pesquisa, 2020.

De acordo com os dados do Quadro 1, dos 38 IFs, 16 resolveram suspender suas atividades a distância em todos os níveis, possivelmente em razão da falta de acessibilidade de parte dos estudantes a esses ambientes, por falta de conexão à internet. O IFCE iniciou a retomada das atividades não presenciais a partir de 28/05. Embora os dados referentes ao levantamento de informações junto às comunidades 
internas dos IFs sobre o acesso à internet não tenham sido sistematizados neste estudo, quando da busca pelas demais informações objeto desta pesquisa, foi possível observar que a maioria realizou levantamento junto às suas comunidades acadêmicas para conhecer essa realidade. Essa decisão não parece ter sido aleatória, mas fundamentada em estudos realizados por cada um desses IFs. Por mais que não tivessem realizado levantamento sobre esse problema, os dados das pesquisas realizadas pelo Núcleo de Informação e Coordenação do Ponto BR - NIC.br podem ter contribuído para fundamentar essa decisão.

Conforme esclarecido anteriormente, os institutos IFAP, IFFar, IFTO, IF Catarinense tentaram manter suas atividades remotas, mas suspenderam-nas em maio. Esse monitoramento demonstra a preocupação dos IFs com a oferta de educação igualitária para todos os seus estudantes, assegurando-se, assim, a igualdade de condições de acesso e permanência na escola, conforme preconizado pelo artigo 206 da Constituição Federal. Esses dados também confirmam o pensamento de Assman (2000), para quem a disponibilização de atividades e ou informações em rede virtual não é suficiente para a construção de conhecimentos.

É possível observar, no Quadro 1, não haver diferenças significativas quanto à continuidade das atividades EaD ou não presencial por nível de ensino. Entre aqueles que optaram por utilizar estratégias de ensino a distância, ficou claro que, em geral, não fizeram distinção entre os cursos de graduação e os cursos técnicos. Alguns institutos observaram, como critério, os limites legais quanto à oferta da carga horária a distância, em especial o que estava disciplinado na Portaria MEC no 2.117/2019, como foi o caso de IFAP, IFPA, IFPI, IFPR. O IFSP retomou as atividades a distância, a partir de maio, para os cursos ofertados a distância, mantendo suspensas as atividades não presenciais para os cursos presenciais.

Já os IFs Goiano e ES retomaram suas atividades não presenciais a partir de meados de abril. Essa iniciativa, com certeza, foi tomada após analisar as condições de acesso de seus estudantes. Os IFCatarinense e IFRR retomaram as atividades não presenciais a partir de $1^{\circ}$ de junho, sendo, neste último, em alguns campi. Essas ações demonstram estar com consonância com a aprovação do Parecer CNE/CP no 5/2020, de 28 de abril de 2020. É possível, também, que, durante esse tempo, essas instituições possam ter oferecido cursos para os docentes a fim de capacitá-los para realizar atividades em ambientes virtuais.

Os IFs que não suspenderam seus calendários, conforme Tabela 3, IFAM, IFSC, IFMS, IFSul de Minas, IFTM, também mantiveram as atividades EaD ou não presenciais em todos os níveis de ensino. O IFTM suspendeu essas atividades por um período de 15 dias, conforme demonstra o Quadro 1, para fazer um levantamento dos resultados

Rev. Nova Paideia -Revista Interdisciplinar em Educação e Pesquisa Brasília/DF, v. 2, n. 3. Núm. Esp.. p. 18 - 34 - ANO 2020 ISSN 2674-5976

DOI: $10.36732 /$ riep.v2i3.60 
e, se for o caso, retomá-las a partir de 22/06. Não foi possível encontrar, nos sites, as metodologias utilizadas por esses IFs para monitorar as atividades realizadas pelos campi e os resultados obtidos com a decisão de mantê-las. Apesar disso, entende-se que essa ação considerou não só a realização de atividades em ambientes virtuais, mas também não presenciais, como é o caso do IFAM, conforme esclarecido anteriormente, demonstrando, assim, que houve antecipação do entendimento do próprio CNE em relação a essa questão.

\section{Considerações finais}

Os dados encontrados nesta pesquisa, ao mesmo tempo em que demonstram a preocupação e a responsabilidade dos Institutos Federais em ofertar a seus estudantes o acesso à educação de qualidade proposta por essas instituições, também demonstram que as decisões seguiram as orientações do MEC, do Conif e do Ministério da Saúde. Foi possível, também, perceber que as ações dos IFs levaram em consideração a realidade de cada região e acompanharam, muitas vezes, as decisões dos governos locais. Enquanto Rede Federal de Ensino, apesar de não ser possível identificar ações homogêneas entre todos os IFs, percebe-se que a preocupação maior dessas instituições está voltada para a oferta de educação de qualidade e em condições igualitárias para todos.

É possível que,após a homologação do Parecer CNE/CP nํ 5/2020, de 28 de abril de 2020, todos os IFs cujos calendários foram suspensos a partir de março ou em data posterior farão a reorganização destes considerando a realização de atividades não presenciais, a fim de não prejudicar seus estudantes e dar a eles condições igualitárias de acesso à educação.

As ações tomadas pelos diferentes IFs em todo o Brasil, embora heterogêneas, demonstraram, também, de modo geral, que a preocupação com as condições de salubridade da comunidade acadêmica (estudantes e servidores) se sobrepuseram às preocupações com as questões pedagógicas. Mesmo diante de um cenário marcado por conflitos de narrativas na esfera federal, em que a Presidência da República insistia em uma narrativa de retorno às atividades econômicas, os IFs demonstraram alinhamento às orientações da Organização Mundial de Saúde e às das autoridades sanitárias de saúde, fazendo-se crer que o cuidado com a saúde e com a vida é um princípio de valor inegociável.

Rev. Nova Paideia -Revista Interdisciplinar em Educação e Pesquisa Brasília/DF, v. 2, n. 3. Núm. Esp.. p. 18 - 34 - ANO 2020 ISSN 2674-5976

DOI: $10.36732 /$ riep.v2i3.60 


\section{Referências}

ALMEIDA, Lília Bilati de et al . 0 retrato da exclusão digital na sociedade brasileira.

JISTEM J.Inf.Syst. Technol. Manag. (Online),São Paulo , v. 2, n. 1, p. 55-67, 2005 .

Disponível em <http://www.scielo.br/scielo.php?script=sci_arttext\&pid=S1807-

$17752005000100005 \& \operatorname{lng}=$ pt\&nrm=iso $>$. acessos em 14 jun. 2020.

ASSMANN, Hugo. A metamorfose do aprender na sociedade da informação.Ci.

Inf.,Brasília , v. 29, n. 2, p. 07-15, ago. 2000 . Disponível em

<http://www.scielo.br/scielo.php?script=sci_arttext\&pid=S0100-

$19652000000200002 \& \operatorname{lng}=p t \& n r m=$ iso $>$. acessos em 14 jun. 2020.

BRASIL. Ministério de Educação e Cultura. LDB - Lei no 9394/96, de 20 de dezembro de 1996. Estabelece as diretrizes e bases da Educação Nacional. Brasília : MEC, 1996. Disponível em:https://www.planalto.gov.br/ccivil 03/LEIS/L9394.htm\#art32\%C2\%A74. Acesso em 29/05/2020.

BRASIL. Ministério da Educação. Conselho Nacional da Educação. Nota de Esclarecimento - Covid-19. Em 18 de março de 2020. 2020a. Disponível em:http://portal.mec.gov.br/conselho-nacional-de-educacao/divulgacao. Acesso em 29/05/2020.

c___. Instituto Nacional de Estudos e Pesquisas Educacionais Anísio Teixeira (Inep).

Censo da Educação Básica 2019: notas estatísticas. Brasília, 2020. Disponível em: <http://portal.inep.gov.br/documents/186968/0/Notas+Estat\%C3\%ADsticas++Censo+da+Educação+Básica+2019/43bf4c5b-b478-4c5d-ae17-

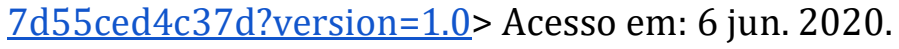

d___. Ministério da Educação. Portaria no 329, de 11 de março de 2020. Institui o Comitê Operativo de Emergência do Ministério da Educação - COE/MEC, no âmbito do Ministério da Educação. Disponível em: $<$ http://download.inep.gov.br/download/portaria n329 de 11032020 institui co mite coe-mec.pdf $>$. Acesso em: 12 jun. 2020.

e___. Instituto Federal de Santa Catarina. Atividades pedagógicas e administrativas presenciais seguem suspensas até 31 de julho. Data de Publicação: 10 jun 2020 20:12 Data de Atualização: 11 jun 2020 15:07. Discponívelem:https://www.ifsc.edu.br/noticia/1940008/atividadespedag\%C3\%B3gicas-e-administrativas-presenciais-seguem-suspensas-at\%C3\%A9-31de-julho. Acesso em 13/06/2020.

Rev. Nova Paideia -Revista Interdisciplinar em Educação e Pesquisa Brasília/DF, v. 2, n. 3. Núm. Esp.. p. 18 - 34 - ANO 2020 ISSN 2674-5976

DOI: $10.36732 /$ riep.v2i3.60 
f____. Instituto Federal de Mato Grosso do Sul. Atividades presenciais continuam suspensas durante o mês de junho. 2020. por Osvaldo Sato. Publicado: 22/05/2020 08h40. Disponível em:

https://www.ifms.edu.br/noticias/2020/atividades-presenciais-continuamsuspensas-durante-o-mes-de-junho. Acesso em 13/06/2020.

g___. Instituto Federal do Amazonas. Portaria Conjunta no 1 , de 11 de março de 2020f. Disponível em: <http://www2.ifam.edu.br/ifam-contra-o-coronavirus $>$. Acesso em: 13 jun. 2020.

BURGESS, Simon; SIEVERTSEN, Hans Henrik. Schools, skills, andlearning: The impact of COVID19 on education. VOX. p. 1 - 4. 2020. Disponível em:https://voxeu.org/article/impact-covid-19-education. Acesso em 28/05/2020.

MORAN, José Manuel. Como utilizar a Internet na educação.Ci. Inf., Brasília , v. 26, n. 2, p. , maio 1997. Disponível em <http://www.scielo.br/scielo.php?script=sci_arttext\&pid=S0100$19651997000200006 \& \operatorname{lng}=$ pt\&nrm=iso $>$. acessos em 14 jun. 2020.

NIC.BR. 0 Núcleo de Informação e Coordenação do Ponto BR - NIC.br. Disponível em:https://cetic.br/pt/tics/domicilios/2019/domicilios/A4/. Acesso em 01/06/2020.

OMS.Director-General'sopeningremarksatthe media briefing on COVID-19 - 11 March 2020. 2020. Disponível em:https://www.who.int/dg/speeches/detail/whodirector-general-s-opening-remarks-at-the-media-briefing-on-covid-19---11march-2020. Acesso em 28/05/2020.

UNESCO. COVID-19 EducationalDisruptionand Response. Disponível em:https://en.unesco.org/covid19/educationresponse. Acesso em 28/05/2020

WORLD FOOD PROGRAMME. Disponível em:

$<$ https://www.wfp.org/publications/framework-reopening-schools-report-unescounicef-world-bank-and-world-food-programme>. Acesso em: 30 maio 2020. 